See Article page 2056.

\section{Commentary: Equality does not equal quality}

Yuting P. Chiang, MD, and

Hiroo Takayama, MD, PhD

The optimal timing of coronary artery bypass grafting (CABG) in acute myocardial infarction (AMI) continues to be debated. ${ }^{1-3}$ It remains unclear whether the clinical judgment of surgeons regarding $\mathrm{CABG}$ timing provides any benefit to patients. The purported advantages of earlier intervention are related to revascularization and salvage of ischemic, at-risk viable myocardium. However, earlier CABG also exposes the patient to stressors (eg, crossclamping of the aorta and cardioplegic arrest) that might exacerbate the injury to myocardium that has not yet stabilized, thus increasing operative mortality. Current guidelines are essentially agnostic.

In this issue of the Journal, Bianco and colleagues ${ }^{4}$ describe a propensity score-weighted analysis of 2058 patients who underwent CABG following AMI in their institution, $14 \%$ of whom underwent "early" surgery (ie, within 24 hours of presentation). They conclude that "late" surgery (after 24 hours) was not associated with any significant advantage in operative mortality or longterm incidence of readmission due to major adverse cardiac and cerebrovascular events. Separate subgroup analyses for patients with non-ST-segment elevation myocardial infarction and ST-segment elevation myocardial infarction yielded similar results.

This study is unlikely to conclusively settle the debate on its own, and one reason is that the inclusion criteria may have been too broad. Among patients with AMI being considered for CABG, the timing of surgery is debatable in some patients but also relatively clear-cut in others. For example, life-threatening hemodynamic instability would in most cases prompt emergent intervention, whereas a

\footnotetext{
From the Division of Cardiothoracic and Vascular Surgery, Department of Surgery, Columbia University Medical Center, New York, NY.

Disclosures: Authors have nothing to disclose with regard to commercial support.

Received for publication Dec 8, 2019; revisions received Dec 8, 2019; accepted for publication Dec 8, 2019; available ahead of print Jan 7, 2020.

Address for reprints: Hiroo Takayama, MD, PhD, Division of Cardiothoracic Surgery,

Department of Surgery, Milstein Hospital Building, 177 Fort Washington Ave,

Suite: 7-435, New York, NY 10032 (E-mail: ht2225@cumc.columbia.edu).

J Thorac Cardiovasc Surg 2021;161:2067-8

$0022-5223 / \$ 36.00$

Copyright (c) 2020 by The American Association for Thoracic Surgery

https://doi.org/10.1016/j.jtcvs.2019.12.038
}

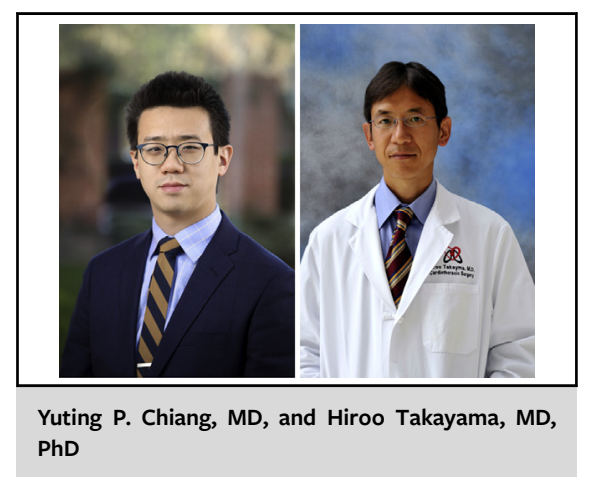

CENTRAL MESSAGE

Lack of difference in outcomes

between early versus delayed

CABG after acute myocardial

infarction does not imply lack of

impact or importance of clinical

judgment.

recent hemorrhagic stroke would in general encourage delaying of exposure to cardiopulmonary bypass and systemic heparinization. Although it is beyond the scope of this study to define such clear-cut clinical scenarios, the inclusion of such patients will undoubtedly impact the outcomes in both the "early" and "late" CABG cohorts and thus distort the comparison of patients in whom timing is truly an open question.

Nevertheless, given the similar outcomes in the "early" and "late" cohorts presented here, and the fact that these cohorts are essentially defined by clinical judgment, the reader might be inclined to conclude that clinical judgment regarding $\mathrm{CABG}$ timing has no impact on outcomes. This would be a major misinterpretation: the impact of clinical judgment regarding CABG timing should be assessed not by measuring whether outcomes in the "early" and "late" cohorts are equal to each other but rather by measuring whether overall quality of care for all patients with AMI requiring $\mathrm{CABG}$ has been improved in general. In other words, reducing operative mortality in the "early" CABG cohort by delaying surgery in patients deemed to be highrisk is not necessarily helpful if those mortalities are simply transferred over to the "late" cohort.

The impact of clinical judgment in this particular study is difficult to ascertain, but the favorable overall outcomes experienced by the patients described here suggest that they have benefited from judicious clinical decision-making. We would 
like to congratulate the authors on their careful analysis of one of the largest single-center cohorts published on this important topic as well as providing excellent day-to-day patient care at the bedside.

\section{References}

1. Anderson JL, Doty JR. Bypass surgery after non-ST-segment elevation myocardial infarction better early than late? JACC Cardiovasc Interv. 2010;3:428-30.
2. Lee DC, Oz MC, Weinberg AD, Ting W. Appropriate timing of surgical intervention after transmural acute myocardial infarction. J Thorac Cardiovasc Surg. 2003; 125:115-20.

3. Davierwala PM, Verevkin A, Leontyev S, Misfeld M, Borger MA, Mohr FW. Does timing of coronary artery bypass surgery affect early and long-term outcomes in patients with non-ST-segment-elevation myocardial infarction? Circulation. 2015;132:731-40.

4. Bianco V, Kilic A, Gleason TG, Aranda-Michel E, Wang Y, Navid F, et al. Timing of coronary artery bypass grafting after acute myocardial infarction may not influence mortality and readmissions. J Thorac Cardiovasc Surg. 2021;161: 2056-64.e4.
See Article page 2056.

\section{Commentary: Coronary artery bypass grafting after acute myocardial infarction: Sound clinical judgment still prevails}

\author{
Katsuhiro Hosoyama, $\mathrm{MD}, \mathrm{PhD}$, and \\ Marc Ruel, MD, MPH
}

Despite numerous studies having focused on the outcomes of coronary artery bypass grafting $(\mathrm{CABG})$ in the setting of acute myocardial infarction (AMI) - denoting a greater operative risk for emergency CABG compared with elective $\mathrm{CABG}$ - the optimal timing of surgical revascularization after AMI remains controversial. In this article, Bianco and colleagues ${ }^{1}$ report on a single-center, retrospective series that compared the short- and long-term outcomes of patients who underwent isolated CABG within 24 hours and after 24 hours from the onset of AMI. The interest of this study relates to its sizable cohort, comprising 2058 patients operated between 2011 and 2017, and the length of followup, with a median of approximately 2 years. The authors compared the clinical outcomes of 292 patients who underwent $\mathrm{CABG}<24$ hours and 1766 patients who had CABG

\footnotetext{
From the Division of Cardiac Surgery, University of Ottawa Heart Institute, Ottawa, Ontario, Canada.

Disclosures: Authors have nothing to disclose with regard to commercial support.

Received for publication Dec 16, 2019; revisions received Dec 16, 2019; accepted for publication Dec 17, 2019; available ahead of print Jan 7, 2020.

Address for reprints: Marc Ruel, MD, MPH, Division of Cardiac Surgery, University of Ottawa Heart Institute, 40 Ruskin St, Ottawa, Ontario, Canada K1Y 4W7 (E-mail: mruel@ottawaheart.ca).

J Thorac Cardiovasc Surg 2021;161:2068-9

$0022-5223 / \$ 36.00$

Copyright (c) 2020 by The American Association for Thoracic Surgery

https://doi.org/10.1016/j.jtcvs.2020.01.001
}

Check for updates

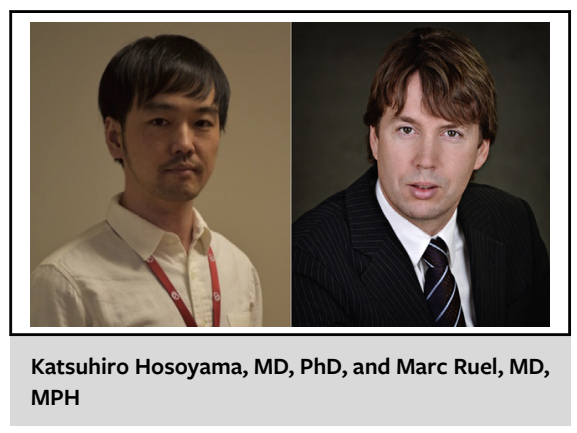

CENTRAL MESSAGE

Contrary to long-held belief, this new study suggests that delaying surgical revascularization after acute myocardial infarction may not be desirable in all cases. However, further analyses will be required to confirm those conclusions.

$\geq 24$ hours after the onset of AMI. Although the perioperative mortality of unadjusted patient cohorts was significantly greater in the $<24$ hours group, there was no such difference after risk adjustment by propensity matching. The authors concluded that delaying surgical revascularization to increase patient stability after AMI may not always be beneficial.

The study has limitations that must be considered before this observation guides mainstream clinical practice. First, patients who underwent CABG within 24 hours were probably assumed to have greater mortality risk due to their increased level of acuity, resulting in confounding by indication through the selection of patients whose upfront risk may have been "worth it." Although propensity matching 